\title{
Sensorimotor expectations and the visual field
}

\author{
Dan Cavedon-Taylor ${ }^{1}$
}

Received: 16 January 2018 / Accepted: 16 September 2018 / Published online: 28 September 2018 (c) The Author(s) 2018

\begin{abstract}
Sensorimotor expectations concern how visual experience covaries with bodily movement. Sensorimotor theorists argue from such expectations to the conclusion that the phenomenology of vision is constitutively embodied: objects within the visual field are experienced as 3-D because sensorimotor expectations partially constitute our experience of such objects. Critics argue that there are (at least) two ways to block the above inference: to explain how we visually experience objects as 3-D, one may appeal to such non-bodily factors as (1) expectations about movements of objects, not the perceiver, or to (2) the role of mental imagery in visual experience. But instead of using sensorimotor expectations to explain how objects are experienced within the visual field, we can instead use them to explain our experience of the visual field itself and, in particular, our experience of its limits; that is, our ever-present visual sense of there being more to see, beyond what's currently within the visual field. Crucially, this inference from sensorimotor expectations to the constitutive embodiment of visual phenomenology is not threatened by the above two challenges. I thus present here a sensorimotor theory of the phenomenology of the visual field, that is, our experience of our visual fields as such.
\end{abstract}

Keywords Action · Mental imagery $\cdot$ Pictorial experience $\cdot$ Puzzle of perceptual presence $\cdot$ Sensorimotor expectations $\cdot$ Visual field

\section{Introduction}

There is a puzzle at the heart of visual phenomenology: surveying the scene before one, objects occlude both parts of themselves and parts of other objects. And yet, for all that, objects don't appear as 2-D façades; rather, objects straightforwardly look 3-D. To that extent, the occluded, rear sides of objects must somehow feature in visual phenomenology. After all, apples look spherical and dice look cubic. But how can that

\footnotetext{
$凶$ Dan Cavedon-Taylor

d.cavedon-taylor@soton.ac.uk

1 University of Southampton, Southampton, UK
} 
be, given that the rear sides of these objects are not seen? This is the so-called puzzle of perceptual presence.

The sensorimotor theorist claims that this puzzle is solved when we factor into visual experience our sensorimotor expectations: although it is true that you cannot now see the rear, occluded sides of the objects before you, you expect to see those occluded sides, were you to move in the relevant ways. Given your first-hand experience of moving through, and acting within, the world, you are familiar with how bodily action makes for predictable changes to visual phenomenology. According to the sensorimotor theorist, it is these expectations that determine your visual phenomenology of the unseen sides of objects, supplying access to such sides. For those sides show up in visual phenomenology not 'as seen', but “as accessible." (Noë 2012, pp. 33, 63, 96) Once we recognise the existence of sensorimotor expectations and consider them a part of visual experience, we thereby have a solution to the puzzle of perceptual presence. $^{1}$

This sensorimotor theory is not just a solution to the puzzle of perceptual presence, it is a radical theory about the nature of visual experience and its relation to both action and cognition. According to sensorimotor theorists, vision is a kind of bodily action. Seeing is not a matter of passively receiving information about objects in one's environment. Seeing is a kind of doing. Or rather, seeing depends upon past performances of doings. Visual awareness of an object's 3-D shape is something that one achieves (or fails to achieve) by bringing to bear the correct (or incorrect) sensorimotor expectations to one's visual encounter with that object. So on this view, visual perception is not what feeds into cognition, which in turn feeds into action. The order of priority is reversed and the boundaries blurred: we see the apple as spherical only because we know, through previous encounters with the apple, how movements of the body this way or that will produce the relevant phenomenal changes to vision to allow us to see the apple's rear side. As Noë puts it (2009, p. 474, 2012, p. 20), to experience the apple as 3-D from a stationary position "you must, in a way, already know it." But this doesn't mean that to visually experience the apple as 3$\mathrm{D}$ is to visually represent the apple's 3-D shape, as a representationalist might hold (Dretske 1995; Tye 1995). Why should it? After all, the apple is right there before you, ready to serve as a repository of information about itself. Perceptual representations, according to the sensorimotor theorist, are redundant. Rather, to be a perceiver is to have implicit, practical mastery of the sensorimotor dependencies that mediate your relationship to the apple. To be a perceiver is to implicitly understand, via acquired sensorimotor expectations, how you are coupled to the environment via these patterns of dependence; that is, how moving through the world makes for systematic changes to your visual experience in predictable, law-like ways. ${ }^{2}$

\footnotetext{
1 In what follows, I restrict my focus to the sensorimotor theory developed by Alva Noë, mainly in his (2004, 2005, 2006, 2007, 2009, 2012, 2015). It might be that what I say has implications for other sensorimotor theories, but I won't assume that to be the case.

2 A potentially useful way to think of the sensorimotor theory is as a naïve realist theory of perception, but one that disagrees with standard versions of that theory on the matter of sensory awareness being psychologically brute (Noë 2005). Standard versions of naïve realism consider sensory awareness to be a sui generis relation, 'acquaintance', between a perceiver and a particular object. Sensorimotor theorists analyse the perceiver-side of such sensory awareness in terms of sensorimotor expectations, which are then,
} 
The sensorimotor theory is motivated, in large part, by its providing an elegant solution to the puzzle of perceptual presence. But sensorimotor expectations are alleged to do more. They are enlisted by the sensorimotor theorist to tell us something important about visual phenomenology; namely, that such phenomenology is constitutively embodied insofar as it is partially composed by sensorimotor expectations. (Hence the blurring of perception, action and cognition.) What it is to see an apple as 3-D, on this view, is in part to have expectations about how the apple would look different, were one to move in the relevant ways. Without sensorimotor expectations, the most one can hope for is visual sensation. This claim goes far beyond seemingly related ones, for instance that an agent's egocentric frame is a constitutive element of visual experience or that visual experience has self-locating content (Cassam 1994; Peacocke 2000). These last two claims do not require any blurring of the boundaries between perception, cognition and action.

The claim that visual phenomenology is constitutively embodied is bold and provocative. It is helpful to contrast it with the more mundane claim that visual phenomenology causally depends upon bodily movement. The causal claim is uninterestingly true. Move your head, and what you see changes. The claim that visual phenomenology depends upon one's body in a mere causal sense makes bodily movement and expectations one thing and visual experience is another. But on the sensorimotor theorist's constitutive account, we are no longer dealing here with two separate existences: bodily action and visual experience. Rather, our sensorimotor expectations are woven into our visual experiences. As Noë (2004, p. 18) says, it is the constitutive claim that "defines" the sensorimotor standpoint.

I begin here by reviewing two objections to the sensorimotor theorist's use of sensorimotor expectations to solve the puzzle of perceptual presence, and which sensorimotor theorists have not yet successfully refuted. The first is that sensorimotor theorists should think that the explanatory role to which they assign sensorimotor expectations could, indeed often is, played by expectations about potential movements of objects, rather than movements of the perceiver (Cavedon-Taylor 2011). The second objection is that our experience of the occluded sides of objects may have nothing to do with expectations about bodily movement and may be a matter of the sensory imagination filling in the relevant details (Thomas 2009; Nanay 2010; Kind 2018). While these are not the only objections that have been put to sensorimotor theorists, they are exceptionally serious ones insofar as they directly challenge the sensorimotor theorist's inference from sensorimotor expectations to vision's constitutive embodiment. However, they are not presented here are decisive objections to the sensorimotor theory, so much as revealing outstanding issues that the theory has yet to fully address.

\section{Footnote 2 continued}

in turn, analysed as practical knowledge that can only be acquired first-hand in virtue of past experience of how bodily movements and action have affected perception. Sensorimotor expectations thus play a key, enabling condition for sensory awareness of objects, along with the presence of those objects themselves. This, then, is the manner in which action is alleged to lie at the heart of perceiving: a creature who could not act could not acquire the relevant practical knowledge or understanding of how movement affects sensory experience, and so would lack the relevant sensorimotor expectations that enable sensory awareness of objects, i.e. as 3-D wholes. 
I then suggest a new explanatory role for sensorimotor expectations, one that evades the above objections: rather that determining how objects appear within the visual field, i.e. as 3-D, our sensorimotor expectations determine the phenomenology of the structural boundaries or limits to that field. In developing this claim, I aim to account for Martin's (1992) phenomenological observation that the visual field is experienced as a mere sub-region of a larger region of space of which it is a part. In a nutshell, Martin's claim is that seeing involves not only visual awareness of the objects in the visual field, but also a visual sense of the world continuing beyond that field. Martin's observation should invite our puzzlement. What falls outside of the visual field is, ipso facto, not seen. So how can seeing ever involve a visual sense of the world continuing beyond what we can see? To my knowledge, this question has not yet been given an answer. What has gone unnoticed, in contemporary discussions of these matters at least, is that this second puzzle is strikingly similar to the puzzle of perceptual presence. Both concern how visual phenomenology at a time outstrips what we see at that time, at least in a strict sense of the term. ${ }^{3}$

The thesis I develop here is thus twofold: (1) our awareness of the limits of the visual field, as limits, is something that sensorimotor expectations well-positioned to explain and (2) they are more apt to explain this than our awareness of the rear, occluded sides of 3-D objects. If what I say is right, then the constitutive embodiment of visual phenomenology can be vouchsafed in a relatively novel and overlooked way: the constitutive embodiment of vision is not so much reflected in how objects are experienced within the visual field, as the puzzle of perceptual presence has it, but in our experience of the limits of that field. I thus present here a sensorimotor theory of the phenomenology of the visual field, our awareness, that is, of our visual fields as such.

\section{The problem of object-active expectations}

Here is an objection to the sensorimotor theorist's attempt to solve the puzzle of perceptual presence: at most, sensorimotor expectations are sufficient to solve that puzzle; they are certainly not necessary. For, just as we expect to see the rear side of the apple, were we to move around it, it is no less true that we expect to see that side, were the apple to move in relation to us, e.g., were it knocked by a passer-by, or blown by the wind, etc. Call the first type of sensorimotor expectation, and which sensorimotor theorists typically focus on, an agent-active one; call the second type an object-active one (Cavedon-Taylor 2011).

The precise nature of the objection is as follows: insofar as agent-active expectations may solve the puzzle of perceptual presence, then so too, by parity of reasoning, can object-active expectations. For, given any potential movement a perceiver $S$ might make relative to an object $o$ to bring its occluded side into view, there is a corresponding potential movement on the part of $o$ such that were $o$ to move that way, the same occluded side would come into $S$ 's view. Both types of expectation, then, are equally

\footnotetext{
3 An anonymous referee points out that Husserl's notion of an inner and outer horizon neatly maps onto the distinction between the two puzzles.
} 
well-placed to explain how one visually experiences objects as 3-D. From this it follows that agent-active expectations are not necessary to experience an object as 3-D. So, the sensorimotor theorist's inference from the existence of agent-active sensorimotor expectations to the constitutive embodiment of visual experience is mistaken. If agentactive expectations can explain how one experiences an object as 3-D, then so too can object-active expectations, and in a non-bodily way.

Still, one might think that object-active expectations are fairly unnatural states, compared with their agent-active cousins, and that, as matter of fact, perceivers draw upon agent-active expectations rather than object-active ones. This would be a mistake, however. If I am sitting static at a café, idly watching the world pass by, I am more likely to draw upon my expectations of how the moving objects before me, e.g., passers-by, busses, etc. would look as they continue to move, or move in different ways, and thereby reveal their occluded sides to me, than I am to consider my own potential movements and how these would reveal the same occluded sides of those objects. Given that the objects in our environment are often in motion, while we may not be, in many situations it is agent-active expectations that appear unnatural and unlikely to be drawn upon.

What the sensorimotor theorist seems to neglect, then, is the dynamic nature of the scenes we are often visually presented with. All of the action is given over to the perceiver. Yet the scenes we look at are rarely static. We see objects moving through scenes. We see people crossing in front of us when we are stopped at traffic lights or see them moving in front of us when stationary or simply walking down the street. At the theatre or ballet, we see the actors and dancers moving in the space before us: parts of them come into view, other parts go out of view. Watching the players and the ball on the football pitch, one does have expectations about how these things would look, were one down on the pitch, moving between them. But one also has expectations about how they will look if they turn (or continue to turn), revealing their previously occluded sides, while one remains stationary in the stands. To say that the rear-sides of the players, actors and passers-by in these examples are experienced 'as accessible' to me via bodily movement may have a grain of truth to it. But, given that these particulars are already in motion, what may be more salient in my visual experience is their actual dynamic movements, never mind my potential own. This, in turn, is surely more likely to prompt expectations about other of their potential movements, i.e. object-active expectations, than it is my own, i.e. agent-active expectations. Thus, objects sometimes show up visual experience not so much as accessible to me via my own bodily movement, but as dynamic objects capable of revealing their occluded sides irrespective of my potential movement.

Sensorimotor theorists are not ignorant of object-active expectations. Consider Noë's claim:

The cube presents itself to me as a cube, precisely because I understand, implicitly, that its appearance would change in determinate ways were I to move in respect of it (or were it to move in respect of me). (2004, p. 119)

From the remark in parenthesis it seems that Noë is prepared to recognise the existence of object-active expectations and also that they represent an alternative account of how we experience objects as 3-D. Given what I have said, one might think this is all for 
the good. As remarked above, there seem some contexts in which it is more natural to picture perceivers as drawing upon these expectations than agent-active ones.

Nevertheless, the admission that object-active expectations can play this explanatory role appears in tension with the sensorimotor theorist's attempt to vindicate the constitutive embodiment of visual awareness. For expectations about one's bodily movement are now rendered optional. Claims such as the following, which are naturally read as stating both the necessity and sufficiency of agent-active expectations, are thereby jeopardised (emphases my own):

[T] he character of our visual experience depends on our embodiment. (2004, p. 26)

Our perceptual sense of the tomato's wholeness-of its volume and backside, and so forth - consists in our implicit understanding (our expectation) that movements of our body to the left or right, say, will bring further bits of the tomato into view. (2004, p. 63)

My proposal is that what explains the perceiver's sense, now, that the occluded surface is present, is his or her expectation (or knowledge, or belief, or anticipation) about what would happen if he or she were to move. (2007, p. 533)

In what does your visual sense of the cubicalness of a cube consist? It consists in your implicit expectation that its appearance would change in the characteristically cubical way as you move in relation to it. (2012, p. 62)

We don't find anywhere in these remarks an acknowledgement of object-active expectations. One reason why this is especially curious is that Noë sometimes insinuates their necessity (2007, p. 476):

[A]n object or quality is perceptually present (i.e. it is an object of perceptual consciousness) when the perceiver understands... that there obtains a physical, motor-sensory relation between the perceiver and object or quality satisfying two conditions:

(1) Movement-dependence: movements of the body manifestly control the character of the relation to the object or quality

(2) Object-dependence: movements or other changes in the object manifestly control the character of the relation to the object or quality

This equal emphasis on both object-dependence (and presumably object-active expectations) along with movement dependence (and presumably agent-active expectations) not only seems a departure from Noë's claims quoted above, it also seems a departure from what he has to say about commonalities between veridical and non-veridical experiences. In cases where one has an illusory experience of a building as 3-D when it is a mere façade, or hallucinates a bulgy 3-D apple where there is none, we are told this is because of agent-active sensorimotor expectations. In particular, the indistinguishability of these non-veridical experiences of 3-D shape from their veridical counterparts is because they "have in common the exercise of the same bodily, sensorimotor skills." (2005, p. 252, emphasis my own) Movement-dependence and object-active expectations exit the picture once again. So we seem pushed back in the 
direction of understanding Noë's view to be that agent-active sensorimotor expectations do the explanatory work in accounting for how we experience objects as 3-D, veridically or not. But then the problem of object-active expectations returns to block the inference from agent-active expectations to the constitutive embodiment of visual phenomenology.

In sum, the fact that there exist patterns of sensory dependence between us and our environment, and about which we have expectations, only supports a constitutively embodied account of visual phenomenology if we ignore object-active expectations. However, such expectations present no less an explanatory solution to the puzzle of perceptual presence than do object-active expectations. If that's right, then from the reality of agent-active expectations, the constitutive embodiment of visual experience does not follow.

\section{The problem of the sensory imagination}

Here is another threat to the sensorimotor theorist's attempt to solve the puzzle of perceptual presence in terms that are constitutively embodied: sensorimotor expectations, agent-active or otherwise, may not have anything to do with why we experience objects to be 3-D. (Hereafter, unless otherwise indicated, by 'sensorimotor expectations' I shall mean the traditional 'agent-active sensorimotor expectations.') My seeing the apple as spherical may be a matter of my imaginatively projecting the image of its rear side into the scene, in the way that I might imaginatively project, say, a bookcase into visual experience when deciding how to arrange furniture in any empty apartment. As is widely recognised, sensory imagination and ordinary visual perception are exceptionally similar in respect of their phenomenologies, so much so that one can be mistaken for the other (see Perky 1910). ${ }^{4}$ Bence Nanay frames this proposal as follows:

My claim is not that imagination is necessary for perception per se, but that the exercise of mental imagery is necessary for... the representation of those parts of the perceived objects that are not visible. In other words, the way we represent the occluded parts of perceived objects is by means of mental imagery. (2010, p. 240)

On this account, apples look spherical and dice look cubic because visual mental imagery fills in one's visual experience of the occluded portions of these objects (see also Thomas 2009; Kind 2018).

There is much that one could say about this attempt to solve the puzzle of perceptual presence, some of it negative (see Briscoe 2011, 2018). All I wish to highlight here is that it is a prima facie plausible solution to the puzzle and one which the sensorimotor theorist must, at the very least, show their solution to be preferable to. Sensorimotor theorists have not, to my knowledge, attempted to meet that challenge. Given that the

\footnotetext{
4 Distinguish three types of imaginings: imagining that such and such is the case, imagining $\mathrm{O}$ 'in one's mind's eye', and imagining $\mathrm{O}$ in one's environment. It is the latter that I am concerned with here. For a useful discussion of these distinctions, see Van Leeuwen (2013).
} 
imagery account of perceptual presence has rich historical roots in Kant, Strawson and Sellars, it cannot simply be ignored.

Moreover, there are some cases of perceptual presence which seemingly could not be explained by appeal to sensorimotor expectations, but which are potential candidates for being explained by the sensory imagination. The cases I have in mind are ones of perceptual presence in pictures. I shall restrict attention to what is sometimes called 'pictorial presence,' and which refers to an object's being experienced as present in a picture's phenomenal space, usually accompanied by the experienced partial occlusion of that object. This sense of presence should be sharply distinguished from the idea that one ever experiences the objects in pictures as being actually present, something which arguably only occurs in trompe l'oeil and unique experimental conditions (for discussion, see Ferretti 2017, 2018, forthcoming a, forthcoming b; Matthen 2005, pp. 315-317; Nanay 2015). In most cases, objects in pictures "look depicted" not present. (Ferretti 2017, p. 378).

Experienced occlusion is not just a feature of ordinary, face-to-face visual experience. In undergoing pictorial experience, i.e. seeing objects in pictures, we typically experience objects in pictorial space to extend behind other objects, no less than when we experience objects face-to-face. As Wollheim (1987, p. 46) puts it, in undergoing pictorial experience, "I am visually aware of the surface I look at, and I discern something standing out in front of, or (in certain cases) receding behind, something else."

However, looking at a picture of an object, one doesn't expect to be able to see the parts of the occluded object within pictorial space by moving around in front of the picture-frame. Pettersson (2011, p. 290) has made this idea particularly vivid: in looking at Michelangelo's painting The Deluge, one has a visual sense of there being a crowd in the foreground, making its way up the hill. Yet all one really 'sees in' pictorial space is a small number of people at the front of the procession. Here, one has a visual sense of the presence in pictorial space of more than what one strictly speaking sees in the surface of the picture. However, one doesn't expect to be able to see the occluded people via moving around in front of the picture (compare Hopkins 2012, sec. 3). One expects the exact opposite: that no movement on one's part will bring them into view. Sensorimotor expectations are a non-starter here as far as explaining the perceptual presence of the crowd in pictorial experience is concerned. By contrast, as Pettersson notes, it is more plausible to think that one experiences the occluded parts of the crowd by means of mental imagery.

The sensorimotor theorist may reply in a number of ways. One response would be to claim that one imaginatively projects oneself into pictorial space in such cases and then imagines having sensorimotor expectations about how things would look different in the scene were one differently located in that space. On phenomenological grounds, this claim seems implausible. In The Deluge, there looks to be a crowd moving up the hill. This is the natural description of what one sees in pictorial space, and it does not take any special effort to experience it. To project oneself into pictorial space and, in addition, imagine having sensorimotor expectations in relation objects in that space, is to engage in mental gymnastics that are more complex than the act they are meant to explain: visually experiencing the large crowd. But suppose we grant that such acts of projection occur and also that they explain cases of pictorially-based 
perceptual presence. At this point, object-active expectations re-enter to challenge the sensorimotor theorist's claim: why not explain one's sense of the crowd in terms of what one would see in pictorial space, were the crowd to (continue) moving up the hill and were the picture a moving image?

Another reply queries the assumption that the sensorimotor theorist needs to give an explanation of pictorially-based perceptual presence, precisely because it is not a case in which the thing visually experienced, i.e. the crowd, is actually present. Yet insofar as we have seen Noë uses sensorimotor expectations to explain non-veridical experiences of presence in illusory and hallucinatory experience, it seems that this is not a reply that he could make. Moreover, were we to grant that sensorimotor theorists can excuse themselves from explaining experienced occlusion in pictures, that would only reveal the limits of the sensorimotor theory. An imagination-based account of perceptual presence can potentially account for experience of both ordinary and pictorial occlusion, and so has greater explanatory power.

What does Noë have to say about the nature of pictorial experience? While Noë $(2012,2015)$ thinks there are several differences between face-to-face seeing and pictorial experience, he thinks that they have the same presence-in-absence phenomenology: objects seen in pictures are genuinely visually experienced, but as absent, in just the way that the occluded portions of objects are. However, for the reasons rehearsed above, whatever explains the pictorial case, it seems, cannot be sensorimotor expectations. So I take it that Noë must give a different account of pictorial presence, thus revealing the explanatory limits of the sensorimotor theory.

In the remainder, I want to explore the idea that there is a different role that sensorimotor expectations might play in relation to visual phenomenology. Crucially, this role is not threatened by either object-active expectations or considerations of the sensory imagination. Moreover, this role would potentially satisfy the sensorimotor theorist's desire to vindicate the constitutive embodiment of visual phenomenology. The role I have in mind for sensorimotor expectations is that they determine the phenomenal character of our experience of our visual fields as such; that is, our experiencing our visual field as a sub-region of a larger region of space of which it is a part. As mentioned in earlier sections, I see the above objections as revealing outstanding issues that the sensorimotor theorist must address, rather than knock-down objections. Crucially, they are challenges to the inference from sensorimotor expectations to the constitutive embodiment of visual phenomenology. This inference, I will argue, is not challenged by the above objections when the visual phenomenology to be explained switches to the visual phenomenology of the visual field. Moreover, even if the sensorimotor theorist can reply to the above objections, I take it that they should welcome expanding the explanatory benefits of sensorimotor expectations in the way I shall now outline.

\section{Martin's field}

Martin (1992) has proposed an influential account of the notion of the visual field, one that is distinct from any notion of a purely phenomenal field of private mental entities such as sense-data or sensational properties (see Price 1932; Peacocke 1983, 
respectively). Martin's visual field is a mind-independent field including not only the objects in the scene before one, but also the space within that field.

In explicating the notion of such a field, Martin principally focuses on the way in which empty space shows up for us in visual experience as locations at which something is not, but could, be seen. The hole in a polo mint, for example, is not a point in space at which one lacks visual experience. That hole is visually experienced as a point in space at which an object is not seen, but would be, were one there.

Martin's observation about the way we see empty space is an observation about how things visually appear within the visual field. But both Richardson (2010) and Soteriou $(2011,2013)$ have noticed that there is a closely connected thesis, implicit in Martin's thinking, concerning how one experiences the boundaries of such a field. Richardson writes:

I think we can make best sense of this notion of the visual field in terms of the claim that we are in some sense aware of the cone-shaped boundaries or limitations of the visual field. Vision has a field, in this sense, in that we are aware of its boundaries in visual experience. (2010, p. 232)

Soteriou puts his finger rather nicely on the phenomenology of Martin's notion of a visual field; that is, what it is like, experientially, to have visual awareness of such a field, as a field:

[W]hen looking straight ahead, any region of space in front of you that you are thereby aware of is presented as a $s u b$-region of a region of space that has that sub-region as part... [I]t may be said that you are visually aware of something like a cone of physical space in front of you, and we might think of the boundaries of this cone as the boundaries of your visual field. (2011, p. 193)

\section{Soteriou continues:}

Rather than thinking of the boundaries of the visual field as boundaries of some thing one is sensing, we should think of the boundaries of the visual field in terms of one's sensory limitations. That there are limits to what can now be sensed that are due to one's sensory limitations... brings with it the idea that there is more to be sensed beyond those sensory limits, hence the idea that your visual awareness of the region of space in front of you is in some sense an awareness of the region as a sub-region of a region of space that has that sub-region as part. That you visually experience a region of space in front of you in this way is an important part of the conscious character of visual experience. (Ibid., emphasis my own)

The idea here is not just that the boundaries of our visual field delimit visual awareness; rather, they show up in the phenomenology of visual consciousness in that very way: they show up as limitations or restrictions. In experiencing the edges of one's visual field in this way, one has a sense of there being more to be seen on the other side of such limitations, e.g., beyond one's current visual field. Call this phenomenological feature of vision 'visual field phenomenology.' It is visual awareness of one's visual field as such; that is, of one's visual field at a time as constituting only a limited portion of all that is around one to be seen. (For more on Martin's notion of a visual field, see also Phillips 2013; Mac Cumhaill 2015.) 


\section{A sensorimotor theory of visual field phenomenology}

As far as I am aware, no explanation has been given for visual field phenomenology; that is, why it should be that one's visual field is experienced in the manner described above: as a limited portion of all that is around one to be seen. Martin, Richardson and Soteriou all comment that the visual field is a 'structural' or 'invariant' phenomenological feature of visual experience. The idea is this: although the objects of vision may change from one visual experience to the next, one thing remains constant: a field-like structure, something that is reflected in the phenomenology of all visual experiences. This would make the visual field potentially apt to explain what it is that makes visual experiences visual and not, e.g., tactual, since touch likewise involves awareness of objects and their spatial properties. Indeed, this idea is defended by Martin (1992).

But visual field phenomenology should not be taken to be a brute, unexplainable fact. That the limits of our visual field show up for us as limits is something that needs explaining, especially if one were to take it that such a field can potentially individuate vision. But independent of whether the notion of Martin's visual field can do that for us, its phenomenological properties present an underappreciated puzzle: how can it be that, at any one time, we have a visual sense of the world continuing, out of view, beyond the limits of our visual field? In particular, how is such a thing possible, given that we cannot, in principle, see beyond the limits of that field at a time?

This puzzle, what we can call the puzzle of visual field phenomenology, has a structure exactly similar to the puzzle of perceptual presence. The puzzle of perceptual presence concerns our visual sense, at any one time, of there being more to the objects that fall within the visual field than what projects to our eyes at that time; for insofar as we visually experience objects to be 3-D, we are visually aware of their occluded sides. The puzzle of visual field phenomenology likewise concerns how visual phenomenology, at a time, goes beyond what we can strictly speaking see at that time: we cannot, now, see beyond the limits of our visual field, but we have a visual sense, now, of there being more to be seen; for we are visually aware of the visible world's continuation beyond the limits of the visual field. The world does not look to end at the edges of vision, just as the objects of sight do not look to be 2-D façades.

While the puzzle of perceptual presence concerns how things appear to us within the visual field, the puzzle of visual-field phenomenology concerns how the limits of that field appear to us: as preventing us from seeing what else there is to be seen. My claim is as follows: that we should experience the limits of the visual field in this way, i.e. as restricting visual awareness, is something that sensorimotor expectations, agent-active ones, are well-placed to explain. We have a sense, now, that the visual world extends beyond the limits of our visual field because we expect to see more, were we to move, e.g., our eyes, heads, bodies, etc. in the relevant ways. On this account, the sense in which visual experience is constitutively embodied in its phenomenology is not a matter of our having a visual sense of the existence of more things inside of the visual field than we can strictly see, i.e. the occluded, rear-sides of objects. Rather, visions' being constitutively embodied in its phenomenology is reflected in the very structure of vision: its field-like organisation. On this view, vision is constitutively embodied in its phenomenology insofar as it features in our awareness of the limits of 
the visual field that they are limits which can be lifted by bodily action. Bodily action is thus partly constitutive of our visual sense of the existence of a visible world outside of sight's field.

The visual field's phenomenology_our visual sense of there being more to see, outside vision - can be understood as a matter of our expecting to find more, should we move our heads, eyes, bodies, etc. On this proposal, the sense in which the phenomenology of visual perception is constitutively embodied shows up in the invariant, structural phenomenology of the visual field itself, something that may be part of vision's very nature, rather than its being reflected in the individual appearances of whatever objects happen to be within that field.

\section{Objections revisited}

I claim that sensorimotor expectations explain the phenomenology of the visual field, thereby solving a puzzle about its phenomenology. Sensorimotor theorists enlist such expectations to solve the puzzle of perceptual presence. Yet we have seen there are (at least) two objections to that, traditional use of sensorimotor expectations and which block any inference from the existence of sensorimotor expectations to the constitutive embodiment of visual phenomenology: the existence of object-active expectations and the plausible idea that sensory imagination is responsible for filling in the details of the experience. In what follows, I argue that neither of these objections thwarts the use of sensorimotor expectations to explain visual field phenomenology. Neither objection, that is, blocks the inference from sensorimotor expectations to the constitutive embodiment of visual experience, when such expectations concern how things appear outside, rather than inside, the visual field.

\subsection{Object-active expectations}

What does one's visual sense of the occluded, rear-side of a 3-D object consist in? Sensorimotor theorists answer: agent-active sensorimotor expectations. But if so, they should likewise think the answer can be, indeed often is: object-active expectations (Cavedon-Taylor 2011). One expects to see the rear side of a 3-D object not only if one moves in the relevant ways, but if that 3-D object itself moves (or continues moving, if already in motion).

Object-active expectations supply a rival solution to the puzzle of perceptual presence, but not the puzzle of visual field phenomenology. That is, such expectations cannot explain one's visual sense of the world continuing out of view beyond the limits of one's visual field. Now, it is doubtless true that one expects to see more, should more objects present themselves in one's visual field. But this expectation, which is the relevant analogue of object-active sensorimotor expectations, is insufficient to generate a sense of the visible world continuing out of view, beyond the limits of one's visual field. For it is consistent with an object appearing in one's visual field, even at its edges, that this object came into existence at the point in space that projects to that relevant limit. An experience of an object's appearing at the edge of the visual field 
cannot, by itself, carry with it a sense of there being anything outside of the visual field. At most, experience of an object's appearing at the limits of the visual field, or experience of its moving between the limits of the field, e.g., along the horizontal axis, could be taken as an indication, or sign or symptom, of the world's continuing out of view. The same is true of objects that come into view at the limits of the vertical axis, as well as at the field's distant limits. To visually register an object's appearance on the horizon is to see something from whose presence one may infer the visible world's continuation beyond that limit.

Contrast the way in which an object's activity within the visual field, e.g., its turning this way or that, gives one more than a mere sign or symptom of there being more to the object than one initially experienced. An object's rotating and revealing its occluded, rear-side gives one perceptual confrontation with that hidden side. Hence object-active expectations are rivals to agent-active ones as far as solving the puzzle of perceptual presence is concerned, but not as far as the puzzle of visual-field phenomenology is concerned. An object's passing from left to right, across the entirety of such a field, is in no way visual confrontation with matters outside of the visual field. Hence, no analogue of object-active expectations can solve the puzzle of visual field phenomenology. Expectations about the movement of 3-D objects within the field are insufficient to generate a sense of the presence of the visible world continuing outside of it.

\subsection{The sensory imagination}

According to the sensorimotor theorist, one's visual sense of the rear side of an apple within the visual field constitutively depends upon one's sensorimotor expectations. We have seen that there is another option: one fills in the details with sensory imaginings, passively projecting the rear side into the visual field (Thomas 2009; Nanay 2010; Kind 2018). We have also seen that this alternative account of perceptual presence is arguably more explanatory insofar as it, but not agent-active sensorimotor expectations, is poised to explain cases of perceptual presence in pictures (Pettersson 2011).

This projective use of the sensory imagination is a candidate explanation of one's visual sense of the occluded, rear-sides of objects within the visual field and is thereby a potential solution to the puzzle of perceptual presence. But sensory imaginings cannot, on pain of incoherence, explain one's visual sense of the visible world's stretching beyond the limits of the visual field. They cannot, that is, solve the puzzle of visual field phenomenology. For one cannot hope to appeal to the projection of images within the visual field to explain our sense of the presence visible objects outside of that field. The only type of projection of imagery that might explain that would be one that involved projecting imagery outside of the visual field. Yet it is entirely unclear what such an act could consist in. For, unless the projecting of imagery into egocentric space is understood to be the projecting of an image within the visual field, it seems that what one is actually doing is tokening the image in the phenomenal space of the 'mind's eye.' There seems no coherence to the idea that one can project mental imagery into egocentric space, yet not within the visual field. 
By contrast, we have a clear idea of the act of projection invoked by Nanay and others in their attempt to solve the puzzle of perceptual presence via appeal to the sensory imagination. From the armchair, such episodes of imaginatively projecting objects and shapes into the visual field play a range of roles for us, including action-guiding and scene-segmenting or attentional ones. Confronted with a skunk, one may guide one's movements by projecting imagery of the skunk's spray and also project imagery of the path to take in order that the spray be avoided (Van Leeuwen 2011). Staring into the night sky, one's visual system may organise the stars into constellations by imagining lines connecting them (Briscoe 2018). Such acts of imagery projection within the visual field are not just available for us to speculate about from the armchair, but are empirically tractable too (Perky 1910; Segal 1972; Brockmole et al. 2002; Gosselin and Schyns 2003; Keogh and Pearson forthcoming).

Hence, the sensory imagination can supply a relatively comprehensive solution to the puzzle of perceptual presence, but not, it seems, a solution to the puzzle of visual field phenomenology.

\section{Conclusion}

On the account I've presented here, the phenomenology of visual experience is constitutively embodied. But contrary to the claims of sensorimotor theorists, that embodiment need not concern how things appear within the visual field, i.e. as whole 3-D objects with occluded, rear sides. Rather, the embodiment of visual phenomenology concerns, and is reflected in, the limits of our visual fields being experienced as such. That is, visual perception is embodied insofar as it is part of the phenomenology of visual awareness that seeing involves a visual sense of there being more to see, beyond what currently falls within bounds of our visual field. The world looks to extend beyond the limits of what we currently see and this is a matter of our expecting to see more of the world, were we to move, e.g., our eyes and bodies, in the relevant ways. This makes vision constitutively, and not merely causally, embodied insofar as the claim is that there is a structural, invariant feature of vision, its field-like structure and phenomenology, that is comprised by our sensorimotor expectations. Again, it is worth restating that even if the traditional sensorimotor theorist's account were not jeopardised along the lines I have argued above, the view presented here would still represent a novel account of the constitutive embodiment of perceptual phenomenology. It is also worth stating that this view preserves the sensorimotor theorist's claim that there exists a substantial degree of conceptual overlap between vision, action and cognition: the limits of the visual field show up in visual phenomenology as limits because we expect to see more were we to move in the relevant ways. Our sensorimotor expectations are thereby made constitutive elements of our visual experiences, not by constituting how the objects of vision appear to us, i.e. as 3-D, but by constituting the invariant structure of vision itself.

Acknowledgements Thanks to Bence Nanay and Dominic Gregory for comments on earlier versions. Thanks also to two of the journal's anonymous referees and editors for their helpful comments. This research was funded by FWO Odysseus Grant G.0020.12N. 
Open Access This article is distributed under the terms of the Creative Commons Attribution 4.0 International License (http://creativecommons.org/licenses/by/4.0/), which permits unrestricted use, distribution, and reproduction in any medium, provided you give appropriate credit to the original author(s) and the source, provide a link to the Creative Commons license, and indicate if changes were made.

\section{References}

Briscoe, R. (2011). Mental imagery and the varieties of amodal perception. Pacific Philosophical Quarterly, $92,153-173$.

Briscoe, R. (2018). On the uses of make-perceive. In F. Macpherson \& F. Dorsch (Eds.), Perceptual memory and perceptual imagination. Oxford: Oxford University Press.

Brockmole, J., Wang, R., \& Irwin, D. (2002). Temporal integration between visual images and visual percepts. Journal of Experimental Psychology: Human Perception and Performance, 28, 315-334.

Cassam, Q. (1994). Self and world. Oxford: Oxford University Press.

Cavedon-Taylor, D. (2011). Perceptual content and sensorimotor expectations. Philosophical Quarterly, 61, 383-391.

Dretske, F. (1995). Naturalizing the mind. Cambridge: MIT Press.

Ferretti, G. (2017). Are pictures peculiar objects of perception? Journal of the American Philosophical Association, 3, 372-393.

Ferretti, G. (2018). Visual feeling of presence. Pacific Philosophical Quarterly, 99, 112-136.

Ferretti, G. (forthcoming a). The neural dynamics of seeing-in. Erkenntnis.

Ferretti, G. (forthcoming b). Perceiving surfaces (and what they depict). In B. Glenney \& J. Silva (Eds.), The senses and the history of philosophy. Routledge.

Gosselin, F., \& Schyns, P. (2003). Superstitious perceptions reveal properties of internal representations. Psychological Science, 14, 505-509.

Hopkins, R. (2012). Seeing-in and seeming to see. Analysis, 72, 650-659.

Keogh, R., \& Pearson, J. (forthcoming). The blind mind: No sensory visual imagery in Aphantasia. Cortex.

Kind, A. (2018). Imaginative presence. In F. Dorsch \& F. Macpherson (Eds.), Perceptual imagination and perceptual memory. Oxford: Oxford University Press.

Mac Cumhaill, C. (2015). Perceiving immaterial paths. Philosophy and Phenomenological Research, 90, $687-715$.

Martin, M. (1992). Sight and touch. In T. Crane (Ed.), The contents of experience. Cambridge: Cambridge University Press.

Matthen, M. (2005). Seeing, doing and knowing. Oxford: Oxford University Press.

Nanay, B. (2010). Perception and imagination: Amodal perception as mental imagery. Philosophical Studies, $150,239-254$.

Nanay, B. (2015). Trompe l'oeil and the dorsal/ventral account of picture perception. Review of Philosophy and Psychology, 6, 181-197.

Noë, A. (2004). Action in perception. Cambridge: MIT Press.

Noë, A. (2005). Real presence. Philosophical Topics, 33, 235-264.

Noë, A. (2006). Experience without the head. In T. Gendler \& J. Hawthorne (Eds.), Perceptual experience. Oxford: Oxford University Press.

Noë, A. (2007). Understanding action in perception: Replies to Hickerson and Keijzer. Philosophical Psychology, 20, 531-538.

Noë, A. (2009). Conscious reference. Philosophical Quarterly, 59, 470-482.

Noë, A. (2012). Varieties of presence. Cambridge: Harvard University Press.

Noë, A. (2015). Strange tools. New York: Hill \& Wang.

Peacocke, C. (1983). Sense and content. Oxford: Oxford University Press.

Peacocke, C. (2000). Being known. Oxford: Oxford University Press.

Perky, C. (1910). An experimental study of imagination. American Journal of Psychology, 21, 422-452.

Pettersson, M. (2011). Seeing what is not there: Pictorial experience, imagination and non-localization. British Journal of Aesthetics, 51, 279-294.

Phillips, I. (2013). Hearing and hallucinating silence. In F. Macpherson \& D. Platchias (Eds.), Hallucination. Cambridge: MIT Press.

Price, H. H. (1932). Perception. London: Methuen. 
Richardson, L. (2010). Seeing empty space. European Journal of Philosophy, 18, 227-243.

Segal, S. (1972). Assimilation of a stimulus in the construction of an image: The Perky effect revisited. In

P. Sheehan (Ed.), The function and nature of imagery. New York: Academic Press.

Soteriou, M. (2011). The perception of absence, space, and time. In J. Roessler, H. Lerman, \& N. Eilan (Eds.), Perception, causation, and objectivity. Oxford: Oxford University Press.

Soteriou, M. (2013). The mind's construction. Oxford: Oxford University Press.

Thomas, A. (2009). Perceptual presence and the productive imagination. Philosophical Topics, 37, $153-174$. Tye, M. (1995). Ten problems of consciousness. Cambridge: MIT Press.

Van Leeuwen, N. (2011). Imagination is where the action is. Journal of Philosophy, 108, 55-77.

Van Leeuwen, N. (2013). The meanings of "imagine" part I: Constructive imagination. Philosophy Compass, 8, 220-230.

Wollheim, R. (1987). Painting as an art. Princeton: Princeton University Press. 